\title{
BMJ Open Study protocol epidemiology of inflammatory bowel disease in childhood and adolescence: a systematic review
}

\author{
Jens Weidner (D) , Ivana Kern, Ulf Manuwald, Joachim Kugler, Ulrike Rothe (D)
}

To cite: Weidner J, Kern I, Manuwald U, et al. Study protocol epidemiology of inflammatory bowel disease in childhood and adolescence: a systematic review. BMJ Open 2020;10:e037669. doi:10.1136/ bmjopen-2020-037669

- Prepublication history for this paper is available online. To view these files, please visit the journal online ()

Received 18 February 2020 Revised 14 August 2020

Accepted 11 September 2020
Check for updates

(C) Author(s) (or their employer(s)) 2020. Re-use permitted under CC BY-NC. No commercial re-use. See rights and permissions. Published by BMJ.

Faculty of Medicine "Carl Gustav Carus", Health Sciences/ Public Health, Technische Universität Dresden, Dresden, Germany

Correspondence to

Mr Jens Weidner;

jens.weidner@tu-dresden.de

\begin{abstract}
Introduction The incidence and prevalence of chronic inflammatory bowel diseases in childhood and adolescence is increasing and varies internationally. The systematic literature review aims to describe international epidemiological trends of chronic inflammatory bowel diseases in the child and adolescence age. A period from 1970 to 2019 will be taken into account when searching for suitable studies as well as geographical differences in the development of incidences will be presented.

Methods and analysis The literature databases PubMed and Embase will be searched for the period from 01 January 1970 to 31 December 2019 using linked keywords. A manual search in bibliographies of already published and relevant systematic reviews will complete the systematic literature search. The included studies will be combined in a qualitative and quantitative synthesis and statistically evaluated.

Ethics and dissemination Ethical approval is not required for this study as it is a systematicreview. The results will be submitted to peer-reviewed journals and presented in national andinternational meetings. This research received no specific grant from any funding agency inthe public, commercial or not-for-profit sectors. This systematic review protocol was registeredwith the International Prospective Register of Systematic Reviews (PROSPERO-NR:CRD42020168644).
\end{abstract}

\section{INTRODUCTION}

Inflammatory bowel diseases (IBD) with the three manifestations Crohn's disease (CD), ulcerative colitis (UC) and indeterminate colitis (IC) are chronic inflammations of the gastrointestinal tract. Characteristics of these diseases are recurrent or persistent inflammatory activity with concomitant increased nutrient loss with increased nutrient requirements. ${ }^{1}$ Consequences can be expressed in deficiency symptoms, growth and development retardation and in psychological form. Due to their chronic relapsing course, these diseases have an influence on the physical, psychosocial and professional development of children and adolescents. ${ }^{3}$ The aetiology of these diseases is still largely unexplained. For a large time, IBD was considered as disease of the western industrial nations. It was little

\section{Strengths and limitations of this study}

The systematic review includes a literature search for a period of 49 years of published international studies on the epidemiology of inflammatory bowel diseases in childhood and adolescents. This makes it possible to analyse international trends.

- By collecting geographical data, a description and analysis of geographical differences regarding the development of incidence rates is possible.

- The systematic review is limited by the search in two electronic databases.

known about the development of the incidence of paediatric IBD in non-industrialised countries. The epidemiology of paediatric IBD changed at the beginning of the $21^{\text {st }}$ century. ${ }^{4}$

The latest, international, epidemiological studies of paediatric IBD report an increasing number of children and adolescents with $\mathrm{CD}$ as well as UC and suggest that the incidence could also increase rapidly in nonindustrialised countries. ${ }^{56}$ At the same time, studies have shown an increasing incidence of paediatric IBD among ethnic groups where IBD was previously uncommon. This suggests an epidemiological shift to emerging nations. $^{4}$

The medical relevance to treat children and adolescents with IBD is still existent and based on the hypothesis, that the number of paediatric IBD is increasing accompanied by a general shift towards non-industrialised countries and towards an earlier onset of IBD in children and adolescents in industrial and non-industrial states. It is necessary to review the international incidence development of paediatric IBD on the basis of a systematic review.

\section{Objective and research questions}

The objective of the systematic review is to describe changes in the incidence and prevalence rates of paediatric IBD over the period 
from 1970 to 2019. It also focusses on geographical differences and factors that can be the cause of the diseases. Therefore, the following primary questions are:

1. How have been the incidence and prevalence of IBD developed internationally from 1970 to 2019?

2. Which geographical differences and trends can be identified?

Secondarily, the following questions are of interest:

1. Which phenotypes according to the Paris classification can be identified in paediatric IBD?

2. Is their frequency influenced by geographical location, age, gender and family predisposition?

\section{METHODS AND DESIGN}

Patient involvement

No funds for patient participation are provided for this systematic review. The research work is therefore carried out without patient participation. However, the results of this study will be made available to the public.

\section{Inclusion criteria}

The inclusion criteria for the review are corresponding to the following PICOS scheme:

\section{$P$ - population}

For the review, children and adolescents aged 0 to 18 are relevant and will be included in the literature search.

\section{I - interventions}

Since the review is an epidemiological analysis, no studies of medical interventions in IBD are included. Only studies covering the prevalence and incidence of IBD and those reporting the methods of making diagnosis are included.

\section{C - comparison}

We will compare the incidence of paediatric IBD by age group (in 5-year steps), by gender, by geographical location and by clinical characteristics. We intend to compare ethnicity, in terms of the incidence of paediatric IBD, and familial predisposition, if the data are sufficiently available.
0 - outcome and outcome measurement

Outcome includes incidence and prevalence estimates in $\mathrm{CD}, \mathrm{UC}$ and IC.

\section{S - study types}

For the review, the following study types are included in the context of the epidemiology of IBD:

Population-related cohort studies, register studies, prevalence studies and cross-sectional studies. All of these include incidence and prevalence estimates for chronic IBD in childhood and adolescence. Therefore, not mentioned at this point, study types are excluded (see PICOS in table 1).

\section{Exclusion criteria}

Systematic reviews, meta-analyses, case control studies, as well as case studies containing incidence or prevalence estimates of chronic IBD will be excluded. Studies that contain incidence and prevalence estimates but do not report methods for obtaining a diagnosis or from which the diagnostic criteria are not clearly discernible will be excluded, too.

\section{Literature search}

In order to obtain a comprehensive overview of the epidemiology of IBD and to be able to present trends, the systematic literature search will start on 01 January 1970. Studies with the above inclusion criteria until 31 December 2019 will be considered.

\section{Electronic bibliographic databases}

The systematic literature review will be conducted by two project participants in the PubMed (MEDLINE) and Embase via Ovid electronic databases to identify studies on incidence and prevalence estimates of IBD. The search strategy will include only terms that involve the epidemiology of IBD using the Boolean operators 'OR' and 'AND'. In respect of the inclusion criteria, an age limit will be made to the childhood and adolescence. A language restriction of the search should not be done. The search strategy is shown comprehensibly in online supplemental appendix 1 .

\begin{tabular}{lll}
\hline \multicolumn{2}{l}{ Table 1 PICOS - scheme } & \\
\hline & Inclusion criteria & Exclusion criteria \\
\hline $\begin{array}{l}\text { Population } \\
\text { Intervention }\end{array}$ & $\begin{array}{l}\text { Children and adolescents aged 0 to 15 years } \\
\text { Incidence/prevalence }\end{array}$ & No incidence/prevalence estimates \\
\hline $\begin{array}{l}\text { Comparison } \\
\text { Outcome }\end{array}$ & $\begin{array}{l}\text { Age groups (5-year steps), gender, geographical } \\
\text { features, clinical characteristic }\end{array}$ & - \\
Study types & $\begin{array}{l}\text { Cohort studies and register studies, respectively, } \\
\text { prevalence studies and cross-sectional studies, } \\
\text { respectively (population based) }\end{array}$ & $\begin{array}{l}\text { No IBD, studies with unreported diagnostic criteria } \\
\text { analyses, case studies }\end{array}$ \\
\hline
\end{tabular}

CD, Crohn's disease; IBD, inflammatory bowel diseases; IC, indeterminate colitis; UC, ulcerative colitis. 


\section{Additional manual literature search}

In addition to the electronic search in PubMed and Embase, we will conduct a search in the Cochrane Library for existing systematic reviews. We will check the reference lists of all founded systematic reviews for additional relevant studies.

\section{Study screening and selection}

In order to determine whether the studies found meet the inclusion criteria, a title abstract screening will be carried out in the first step by two independent project participants (JW and UM). Studies that do not meet the inclusion criteria of the title and abstract will be excluded and will not be subject to any further substantive examination. The studies included in the title abstract screening will be then checked in full text by two project participants (JW and UM), independently of each other, to fulfil the inclusion criteria. In case of disagreement a third reviewer will consult UR or IK for a decision.

\section{Data extraction}

For data extraction and synthesis, a prepared, standardised tabular form is used in which the data will be entered according to the Paris classification of the IBD (table 2):

Additionally, the following data will be extracted;

- General study characteristics,

- Study period,

- Geographical location,

- Population (age spectrum and sex),

- Standard population (to calculate age-standardised rates),

- Age groups,

- Methods of diagnostic determination,

- Incidence, prevalence of CD, UC, IC and of IBD in total,

- Clinical characteristics of IBD by Paris classification,

- Factors such as gender, family predisposition and ethnicity.

We will have the data extraction performed by two independent project participants (JW and UM). We will include all data in an Excel spreadsheet. The geographical location, by longitude and latitude of the study sites from the included published studies, will be identified by the GeoPlanner programme and entered into the Excel table. The table will be checked for consistency by two independent project participants (JW and UR) after data extraction.

\section{Evaluation of the report quality}

The report quality is recorded for the included studies. For this purpose, the presence and completeness, respectively, of information regarding the study design, study execution and evaluation is checked ${ }^{7}$ in order to draw conclusions about the study quality, whereby the quality of the reports will not be used as a surrogate parameter for the quality of the respective studies. The included studies will be each reviewed by two independent project
Table 2 Paris classification of IBD in childhood and adolescence

\begin{tabular}{|c|c|c|}
\hline & Category & Definition \\
\hline \multicolumn{3}{|l|}{ Crohn's disease } \\
\hline \multirow[t]{2}{*}{ Age at diagnosis } & A1a & 0 to $<10$ years \\
\hline & $A 1 b$ & 10 to $<17$ years \\
\hline \multirow[t]{5}{*}{ Localisation } & L1 & $\begin{array}{l}\text { Infestation of the distal third } \\
\text { of the ileum with/without } \\
\text { coecum infestation }\end{array}$ \\
\hline & L2 & Colonic infestation \\
\hline & L3 & Colonic and ileum infestation \\
\hline & $\mathrm{L} 4 \mathrm{a}$ & $\begin{array}{l}\text { Infestation proximal of the } \\
\text { 'Treitz'sche band' }\end{array}$ \\
\hline & $\mathrm{L} 4 \mathrm{~b}$ & $\begin{array}{l}\text { Infestation between } \\
\text { 'Treitz'sche band' and distal } \\
\text { third of the ileum }\end{array}$ \\
\hline \multirow[t]{4}{*}{ Behaviour } & B1 & $\begin{array}{l}\text { Non-stricturing, non- } \\
\text { penetrating }\end{array}$ \\
\hline & B2 & Stricturing \\
\hline & B3 & Penetrating and stricturing \\
\hline & $\mathrm{P}$ & Perianal infestation \\
\hline \multirow[t]{2}{*}{ Growth } & Go & No growth retardation \\
\hline & G1 & Growth retardation \\
\hline \multicolumn{3}{|l|}{ Ulcerative colitis } \\
\hline \multirow[t]{2}{*}{ Age at diagnosis } & A1a & 0 to $<10$ years \\
\hline & A1b & 10 to $<17$ years \\
\hline \multirow[t]{4}{*}{ Localisation } & E1 & Ulcerous proctitis \\
\hline & E2 & $\begin{array}{l}\text { Ulcerous left side colitis } \\
\text { (with spreading distal of the } \\
\text { left colon flexure) }\end{array}$ \\
\hline & E3 & $\begin{array}{l}\text { Extensive infestation (with } \\
\text { distal expansion of the right } \\
\text { colonic flexure) }\end{array}$ \\
\hline & E4 & $\begin{array}{l}\text { Pancolitis (including } \\
\text { intestinal sections proximal } \\
\text { to the right colon flexure) }\end{array}$ \\
\hline \multirow[t]{2}{*}{ Severity } & so & Never heavy activity \\
\hline & S1 & Heavy activity \\
\hline \multirow[t]{2}{*}{ Growth } & Go & No growth retardation \\
\hline & G1 & Growth retardation \\
\hline
\end{tabular}

IBD, inflammatory bowel diseases.

participants (JW and UM) with regard to their reporting quality with the SIGN and CASP checklist. ${ }^{8}$ In addition, risk of bias is assessed for the following risks:

- Recruitment procedure and follow-up.

- Outcome definition and measurement.

- Outcome source and validation.

- Confounding and effect modification.

- Analysis method: methods to reduce research specific bias.

- Funding. 
- Conflict of interest.

It does not rule out studies as a result of their distortion at risk, but the optional rate is presented with due notice in the result.

\section{Data synthesis and analysis}

A synthesis of the included studies will be narratively and descriptively presented in tables and we will present a summary of the incidence in geographical maps. In these tables the data will be contained and evaluated by using methods of descriptive statistics. The data will be stratified according to patients' characteristics. The incidence, prevalence and risk rates will be provided with 95\% CI. Group differences of age and gender will be described by inference statistic tests. The statistical analysis of the data will be done with SPSS 25 and R. If the included studies use the same type of methodology and outcome measurement, we will merge the results in a meta-analysis. Heterogeneity between the studies will be assessed by using $\chi^{2}$ and $\mathrm{I}^{2}$ statistics. An $\mathrm{I}^{2}$ value greater than $50 \%$ does not allow a meta-analytical summary of the results because the use of random-effect models would decrease the accuracy with increasing heterogeneity. If sufficient data of sufficient quality are found, meta-analysis or meta-regression analysis will be performed.

\section{Ethics declarations and dissemination}

This systematic review protocol was registered with the International Prospective Register of Systematic Reviews (PROSPERO-NR: CRD42020168644) on 10 February 2020. Any amendments to the protocol will be documented on the PROSPERO site. Ethical approval is not required for this study as it is a systematic review. The results will be submitted to peer-reviewed journals and presented in national and international meetings.

Contributors JW, IK, UM, JK and UR contributed significantly to the conception and design, the study protocol; JW, UM and UR designed the article, and UR is associated with the final approval of the manuscript.

Funding We acknowledge support by the Open Access Publication Funds of the SLUB/TU Dresden. The funders had no role in study design, data collection and analysis, decision to publish or preparation of the manuscript.
Competing interests None declared.

Patient consent for publication Not required.

Provenance and peer review Not commissioned; externally peer reviewed.

Supplemental material This content has been supplied by the author(s). It has not been vetted by BMJ Publishing Group Limited (BMJ) and may not have been peer-reviewed. Any opinions or recommendations discussed are solely those of the author(s) and are not endorsed by BMJ. BMJ disclaims all liability and responsibility arising from any reliance placed on the content. Where the content includes any translated material, BMJ does not warrant the accuracy and reliability of the translations (including but not limited to local regulations, clinical guidelines, terminology, drug names and drug dosages), and is not responsible for any error and/or omissions arising from translation and adaptation or otherwise.

Open access This is an open access article distributed in accordance with the Creative Commons Attribution Non Commercial (CC BY-NC 4.0) license, which permits others to distribute, remix, adapt, build upon this work non-commercially, and license their derivative works on different terms, provided the original work is properly cited, appropriate credit is given, any changes made indicated, and the use is non-commercial. See: http://creativecommons.org/licenses/by-nc/4.0/.

ORCID iDs

Jens Weidner http://orcid.org/0000-0003-4373-8147

Ulrike Rothe http://orcid.org/0000-0001-9779-7260

\section{REFERENCES}

1 Meier C, Thönneßen C, Rothe U, et al. Chronisch entzündliche Darmerkrankungen bei Kindern und Jugendlichen. Monatsschrift Kinderheilkunde 2006;154:1212-8.

2 Cezard JP, Touati G, Alberti C, et al. Growth in paediatric Crohn's disease. Horm Res 2002;58 Suppl 1:11-15.

3 Buderus S, Scholz D, Behrens R, et al. Inflammatory bowel disease in pediatric patients: characteristics of newly diagnosed patients from the CEDATA-GPGE registry. Dtsch Arztebl Int 2015;112:121-7.

$4 \mathrm{Ng} \mathrm{SC}$, Shi HY, Hamidi N, et al. Worldwide incidence and prevalence of inflammatory bowel disease in the 21 st century: a systematic review of population-based studies. Lancet 2018;390:2769-78.

5 Kaplan GG, Ng SC. Understanding and preventing the global increase of inflammatory bowel disease. Gastroenterology 2017;152:313-21.

6 Molodecky NA, Soon IS, Rabi DM, et al. Increasing incidence and prevalence of the inflammatory bowel diseases with time, based on systematic review. Gastroenterology 2012;142:e42:46-54.

7 Moher D, Jadad AR, Nichol G, et al. Assessing the quality of randomized controlled trials: an annotated bibliography of scales and checklists. Control Clin Trials 1995;16:62-73.

8 Sleith C. Notes on the use of Checklist 3 - Cohort Studies. In: Network SIG, ed. Critical appraisal notes and checklists. Edinburgh: Healthcare Improvement Scotland, 2012. https://www.sign.ac.uk/checklists-andnotes

9 CASP. CASP Checklist for Cohort Study. In: OCfTV H, ed. Critical appraisal skills programme. Oxford, 2018. https://casp-uk.net/casptools-checklists/ 